\title{
The myth of participation in occupational therapy: reconceptualizing a client-centred approach
}

\author{
Anette Kjellberg, Ida Kåhlin, Lena Haglund and Renée Taylor
}

\section{Linköping University Post Print}

N.B.: When citing this work, cite the original article.

Original Publication:

Anette Kjellberg, Ida Kåhlin, Lena Haglund and Renée Taylor, The myth of participation in occupational therapy: reconceptualizing a client-centred approach, 2012, Scandinavian Journal of Occupational Therapy, (19), 5, 421-427.

http://dx.doi.org/10.3109/11038128.2011.627378

Copyright: Informa Healthcare http://informahealthcare.com/

Postprint available at: Linköping University Electronic Press

http://urn.kb.se/resolve?urn=urn:nbn:se:liu:diva-73091 
Running head: Participation in occupational therapy

Title: The Myth of Participation in Occupational Therapy: Reconceptualizing a

\section{Client-Centered Approach}

\section{Authors}

Anette Kjellberg, PhD, RegOT. Department of Social and Welfare studies, Linköping University, Sweden.

Ida Kåhlin, PhD student, MScOT, RegOT. Department of Social and Welfare Studies, Linköping University, Sweden.

Lena Haglund PhD, Ass. Professor, RegOT, Department of Social and Welfare studies, Linköping University, Sweden.

Renée R. Taylor, PhD, Professor, Department of Occupational Therapy, University of Illinois at Chicago, Chicago, Illinois, U.S.A.

\section{Corresponding author}

Address for correspondence:

Anette Kjellberg

Linköping University

Faculty of Health Sciences

Department of Social and Welfare Studies

SE-601 74 Norrköping

Sweden

Telephone: + 4611363279

Telefax: + 4611125448

E-mail: anette.kjellberg@.liu.se 


\begin{abstract}
Participation is often the comprehensive objective of treatment but also an indication of the extent to which the process of occupational therapy is client-centred. The purpose of this study was to explore levels of participation during occupational therapy among clients in the area of mental health from the occupational therapists' perspectives.

Additionally we seek to identify factors that might hinder client participation. Postal questionnaires were sent out to 670 Swedish occupational therapists working with persons with mental illness and learning disabilities. The questionnaire required therapists to rate clients' levels of participation during occupational therapy. Findings indicated the most common level of participation for the clients was interdependent meaning that problems, goals, and plans were identified jointly and collaboratively with the occupational therapist. However, more than $20 \%$ of the clients were described as being dependent. Almost $90 \%$ of the occupational therapists rated client participation in therapy to be very important and nearly $70 \%$ claimed that client participation in general needed to be increased. Occupational therapists rated the primary barriers to participation as being clients' inability to participate and organizational and financial problems. Implications of these findings for education in client-centred practice approaches are discussed.
\end{abstract}

Key words: attitudes, intellectual disabilities, learning disabilities, mental illness, mental health, occupational therapist, practice 


\section{Introduction}

In occupational therapy, participation and its role within client-centred practice has become an important topic in both political and scientific discussions $(1,2)$ An early contribution to this dialogue was the International Classification of Functioning, Disability and Health, ICF. In the ICF participation is defined as a person's involvement in a life situation (3). The ICF put the concept of participation on the map in health care, and it began to address some of the criticisms of traditional medical-model approaches raised in the area of disability studies (4). Moreover, the United Nations Convention on the Rights of Persons with disabilities recently highlighted the importance of participation in society at large (5). Participation, as manifested in improved occupational performance, is often the ultimate aim in occupational therapy. Importantly, it is often overlooked as also being a means in occupational therapy $(4,6,7)$. Kielhofner (4) defined participation as a client's ability to identify problems, identify goals for outcomes, and assist in making plans for the occupational therapy process. The present study explores this focus on participation. Participation as a means is reflected in clientcentred approaches, which are fundamental in occupational therapy practice today $(2,4,7-11)$. A recent review of the evidence indicates that participation is intimately connected with the concept of client-centeredness (7). For example, Sumsion (12) defined being client-centred as valuing and respecting the client and as ensuring that the client is able to participate in decisions regarding his or her own care. Similarly, Hedberg-Kristensson and colleagues (13) define client-centeredness in terms of a mutual dialogue between client and therapist. They emphasize the client's ability to take an active part in conversation with the therapist as a prerequisite for partnership and participation. Maitra and Erway (9) also argue that clientcentred practice depends on participation, with participation defined as active involvement in treatment planning, goal setting, identifying desired occupations, and demonstrating motivation to engage in occupational therapy. Taken together, these findings suggest that 
participation and client-centeredness have been seen as intrinsically linked and traditionally have been viewed from a largely Western viewpoint. According to this viewpoint, clients are expected be capable of and willing to assume a certain degree of power within the relationship (10) and responsibility for investing and engaging in occupational therapy. Importantly, the client-centred approach has been defined variably within the occupational therapy literature $(2,7,11,14,15)$. According to the Canadian perspective $(11,15)$ client perspectives, needs, and desires should be the driving force in therapy. This perspective emphasizes the importance of collaboration, and of recognizing the knowledge, strengths, capacity for choice, and overall predisposition toward independence and autonomy. Client-centred therapy includes the clients' right to participate in occupational therapy as a partner, to be listened to, and to be involved in the decisions regarding the identification of problems, goals and plans for interventions $(11,15)$. Recently, U.S. scholars have argued that being client-centred in occupational therapy involves a highly complex approach to therapeutic reasoning that prioritizes empathic understanding of the client's experience and needs independently of the client's ability to express these things $(2,14)$. Importantly, this perspective does not always mean that the client should be entirely independent in his or her decision-making or that he or she should take the lead in defining problems, establishing plans, or setting goals for outcomes. In fact, this perspective on client-centred therapy does not necessitate that the client make decisions jointly with the occupational therapist. Instead, this perspective endorses being an advocate for the client's welfare and desires, however explicit or subtle they may be. This perspective offers a well-rounded and comprehensive understanding of what it means to be client-centred. Client-centred therapy may involve empowering the client and collaborating during treatment or it may simply mean taking the time to appreciate and respect clients' experience in occupational therapy, whatever it is, and advocate for their needs when they may not be able to do this for themselves (2). In Sweden the client's right to participate in 
occupational therapy is stated in several important laws regarding the practice of occupational therapy (16-18). The importance of client participation is also highlighted in the Swedish Code of Ethics for Occupational Therapists (19). Studies with clients as respondents indicate that occupational therapists should be more aware of clients' desire for participation and involve them more in the planning and process of therapy $(10,13,20,21)$. Of interest, is that all of these findings are based on information gathered from respondents with physical disabilities. Arguably, clients with physical disabilities are a group that has a longer history of self-advocacy and civil rights activities, as compared with clients within mental health care, who have only recently begun to organize against stigmatization and oppression (22).

Because there is so little evidence of how the value of participation is actualized in occupational therapy with clients in mental health settings, persons with mental illness and learning disabilities will be the focus of this study. In this study, we will examine occupational therapists' views of client participation in the therapeutic reasoning process. The purpose of this study was to explore levels of participation during occupational therapy among clients in the area of mental health from the occupational therapists' perspectives. Additionally we seek to identify factors that might hinder client participation.

\section{Materials and methods}

\section{Ethical considerations}

This study was designed in line with the ethical guidelines for research in the humanities and social sciences outlined by the Swedish Research Council (23).

\section{Participants and Procedures}


The selection of participants for this study was made in 2004 with the assistance of the Swedish Association of Occupational Therapists. The Association has approximately $95 \%$ of the total number of Swedish occupational therapists as members (24). All 670 occupational therapists registered by the Swedish Association as working with adults within the mental health area in Sweden were invited to participate. This represented a convenience sample with the only criterion for inclusion being that the therapist was registered as practicing with individuals who either had a mental illness or a learning disability. Therapists in the Association who were seeing any other client groups were excluded from this study. No other inclusion or exclusion criteria were applied.

\section{Data collection}

A self-report questionnaire with opened ended and closed questions was developed in order to collect data for this study. A group, consisting of five occupational therapists working in the mental health area, was asked to review the questionnaire regarding overall comprehension, and face validity. The review assured the face validity of the questionnaire and resulted in only minor revisions regarding linguistics and chronologies of questions.

The final version of the questionnaire began with closed questions assessing demographic data concerning the occupational therapists. The opened-ended questions that followed inquired about the demographics of the five most recent clients that had been involved in occupational therapy evaluation (i.e. gather information concerning the client's situation) and intervention (i.e. identify goals, plan for therapy, implement and review therapy) (2). Next, a series of closed questions required respondents to rate their five clients' levels of participation in the evaluation and intervention phases of therapy. Again, participation was defined according to Kielhofner (2), as the client's ability to identify problems, identify goals for outcomes, and assist in making plans for the therapy process. Three levels based on a 
study by Kjellberg (25) were used to rate participation in occupational therapy: (1)

independence (i.e., the client has identified the problems, goals for outcomes, and/or plans for the therapy process; (2) interdependence (i.e., the problems, goals, and plans were identified jointly and collaboratively with the occupational therapist); and (3) dependence (i.e., the problems, goals, and plans were identified by the occupational therapist without involving the client.

Questions were also asked regarding the barriers that might hinder client participation. Respondents were asked to select the five main barriers from a list of alternatives, such as a) the clients' lack of ability to participate (e.g., define the problem, identify the goal, and plan for therapy, b) organizational and financial problems or c) the clients' lack of knowledge about the problem. It was also possible for the respondents to fill in barriers that they thought were missing on the list. Finally respondents were asked to rate the general importance of client participation and also to report their views about the general need for increased participation when they involved clients in the evaluation and intervention of occupational therapy.

Self-report questionnaires were distributed by post and a cover letter was included that clarified the purpose and the context of participation in this study and information about the voluntary nature of participation and that confidentiality was guaranteed. After one postal reminder 285 (43\%) Occupational Therapists returned the questionnaires. Of this 164 were totally completed and 121 partially completed. All of these questionnaires were included in the study. A partially completed questionnaire meant, in most cases, that the questions concerning the demographics of the clients and the description of their participation were left unanswered. This left a response rate of $43 \%$ where $24 \%$ were totally completed.

Data Analysis 
The data collected in this study were analyzed using SPSS version 14.0. Descriptive data and frequencies are presented as numbers (n), percentages (\%) and means (M).

\section{Results}

\section{Participants}

In total $285(43 \%)$ occupational therapists answered the questionnaire. Of these $173(61 \%)$ reported that they worked with persons with mental illness and $112(39 \%)$ with persons with learning disabilities. The age of the occupational therapists ranged from 24 to 64 years $(M=$ $45,6)$ and the years of working experience ranged from 1 to 40 years $(M=15,5)$. Information about employers was reported by 245 participants. More than half of the participants reported that they were employed by the county council, a little more than one third by the community, and the rest reported that they had a private employer or that their employer was the state government. All representing usual fields of practice for mental health service (see Table I). Almost two thirds reported their main working field in municipalities to be either residential facilities or daily activities/work, or both residential facilities and daily activities/work. More than one third reported that their main working field was hospital treatment, out-patient treatment or both hospital and out-patient treatment.

Regarding post-graduate education (i.e., after completing an occupational therapy program), information was reported by 223 participants (see Table II). Approximately half of the occupational therapists reported that they completed further education after their occupational therapy program. This education was reported to be courses that were specific for occupational therapists, complementary courses to reach higher academic levels in occupational therapy including Master's level studies, but also further education in other fields. Insert Table I and Table II about here 
Occupational Therapists' Perspectives on Client Participation in Occupational Therapy

A majority of the clients were female (59\%), lived in own accommodations (63\%) and 86\% were unemployed. The most frequent diagnoses were psychotic disorders $(22 \%)$, mood disorders (20\%) and mental retardation (18\%).

When it came to the definition of "problems", information was provided for a total of 778 clients. Of these, 95 clients (12\%) were reported to be independent, meaning that the client him-/herself defined the problem, and 510 clients (66\%) were reported to be interdependent, meaning that the problems were defined by the client together with the occupational therapist. One hundred seventy three clients $(22 \%)$ were reported to be dependent, meaning that the problems were defined solely by the occupational therapist. Regarding the "identification of goals for therapy outcomes", information on 775 clients was provided. Of these, 105 clients (14\%) were reported to be independent, 513 clients $(66 \%)$ were reported to be interdependent and 157 clients (20\%) were reported to be dependent. When asked about "plans for the therapy process", information on 776 clients was provided. Of these, 46 clients (6\%) were reported to be independent, 549 clients $(71 \%)$ were reported to be interdependent and 181 clients $(23 \%)$ were reported to be dependent.

\section{Variables that Might Hinder Client Participation in Occupational Therapy}

The participants were asked about five main barriers for client participation. The most frequently identified barriers were a) the client's lack of ability to participate b) organizational and financial problems in the workplace and c) the client's lack of knowledge about the problem and how it might be able to be solved (Table III). Insert Table III about here 
Two hundred eighty-two participants reported information about the importance of client participation in occupational therapy. Of these, 245 (87\%) respondents claimed participation to be very important, 27 (10\%) fairly important, $9(3 \%)$ somewhat important and $1(<1 \%)$ respondent reported it to be not at all important. The need for increased client participation, information was reported by 259 occupational therapists. Of these, $186(72 \%)$ claimed that participation in general needed to be increased.

\section{Discussion}

This study sought to characterize client participation in occupational therapy from the perspective of occupational therapists working in a mental health setting. Although most occupational therapists placed high value upon the need for clients to participate actively in therapy, actual rates of client participation as defined in terms of independence were low. Instead, most therapists characterized their relationships with their clients as interdependent throughout all aspects of therapy.

One of the most valued goals in occupational therapy policy and literature is to support the development of independence for a client. The present study used a three category scale (independence, interdependence and dependence) for measuring participation (25). The most frequently-endorsed level of participation was interdependence regardless of whether it referred to the definition of problems, identification of goals for outcomes or to the identification of plans for therapy. These findings shed new light on previous, dichotomous classification systems and perspectives that have defined participation as either independent or dependent, with independence being more desirable than dependence.

In contrast to previous perspectives, findings from this study beg the question as to whether a client's level of participation is ever, truly independent if therapy is truly client-centred (e.g., 2,14) in nature. A literature review by Kinebanian and Stomp (26) found that values 
surrounding the emphasis on client power, autonomy, independence and voice emphasized within the occupational therapy profession are based on the Western view of the world and influenced by White middle-class values. It may be considered as a dilemma that occupational therapists have a Westernised definition of independence since our results suggest that true client-centred occupational therapy also include interdependence.

It is possible that our professional values can sometimes interfere with our client's values, particularly when clients do not meet our expectations in terms of their ability to communicate with us or function at an independent level $(2,8,14)$. It is during these times when it becomes critical to gain an empathic understanding of these clients and to apply a therapeutic reasoning process that incorporates advocacy and other actions to support clients who are less able to achieve independence in the traditional sense $(2,8)$. Similarly, Whiteford and Wilcock (27) point out the importance of considering that independence is a relative phenomenon and must be related to each unique situation for each person/client. Based on findings from the present study, participation, when defined in terms of independence, can be considered as a myth since interdependence was the most common level of participation. For occupational therapy to meet the needs of a wide range of clients, including individuals such as those with mental illness and learning disabilities who may present increased challenges due to the nature of their impairments, a more comprehensive definition of participation is needed. Participation must be situated within the unique context of the treatment relationship. To be defined as client-centred, this relationship must be shared at a level that is appropriate for the client, in order for that relationship to function effectively enough to engender true participation during therapy and beyond (8).

In this study, we not only examined therapist perspectives on levels of participation, but we also explored barriers to participation as perceived by the occupational therapists. The primary barriers endorsed by the therapists included the perception that clients lacked an 
ability to participate in therapy. Clients were characterized as not having the capacity to describe their problems, set goals, and choose appropriate plans and strategies during therapy. The therapists' perceptions that their clients lacked the ability to engage in and take control of the treatment process was striking. For clients to achieve optimal health and well-being, they need relevant and appropriate interventions and experience benefits from participating in occupational therapy. This type of engagement is the hallmark of client-centred approaches (e.g., 4, 8). Surprisingly in the present study $39 \%$ of occupational therapists referred to the client's ability as a reason for the clients' lack of participation in therapy. As treatment providers, we assume that clients are clients because they have difficulties managing in daily life. The particular impairments that characterized the populations sampled in this study (individuals with learning disabilities and mental illness) involve, by definition, limitations in cognitive functioning, including the ability to recognize and identify problems and plan appropriate courses of action in life. However, these impairments do not preclude these individuals from receiving care that is directed toward meeting their needs. As occupational therapists, it is our duty to use our professional knowledge to support client involvement at levels that are appropriate and comfortable for them. This may require educating clients in different compensatory strategies and conveying a strongly empathic approach within the therapeutic relationship that emphasizes an ongoing striving to understand the client. In addition to these findings, organizational and financial problems were cited, along with clients' lack of knowledge about their problems and how they might be able to be solved. Anecdotal evidence from mental health practice settings supports the found barrier of organizational and financial problems. Many occupational therapists report that caseload demands and time constraints imposed within their settings make it difficult-to-impossible to bring their clients to a level of independence in participation. Even if research has shown that optimal treatment outcomes occur when clients are enabled to control the process, many 
occupational therapists working under time limits would argue that supporting a client to the point of independence takes too much time. It is possible that the best these occupational therapists thought they could do was to either direct their clients' therapy entirely or allow for a process of interdependence to occur. What was promising about our findings was that most occupational therapists consistently characterized their relationships with their clients as interdependent.

Future research should explore how the occupational therapists conceived the concept of interdependence in participation namely did the clients experience interdependence in which they felt understood, fully informed, and supported in their desired levels of participation during occupational therapy. Using qualitative methodology and more precise measurement will be necessary to expand upon the meaning of interdependence in participation and on the nature of occupational therapists' perceptions regarding barriers to their clients' participation in therapy. The assessment of client participation in this paper focused on the occupational therapists' perspectives. If clients were asked the same questions about their level of participation, findings may have been different. Future studies should include clients' perspectives on this issue.

Taken together, these findings suggest that, while most occupational therapists viewed their relationships with their clients as interdependent in nature, many are feeling significant pressure from organizational and financial constraints. Moreover, they lack faith in the fundamental capacities of their clients to direct their own care during therapy. In other mental health disciplines such as psychologists, client-centred approaches argue that all clients possess an innate capacity to take control during therapy, provided that this capacity is accessed within an atmosphere of unconditional positive regard and through a process of empathic understanding (28). It is possible that the occupational therapists responding to our survey lack sufficient training or experience in client-centred approaches to assessment and 
intervention that draw upon this type of empathic understanding as a foundation (e.g., 2,8). These therapists may not be utilizing client-centred occupational therapy assessments to their advantage and may not be applying conceptual practice models intentionally with empathy and with efficiency demands in mind. Moreover, they may have less developed therapeutic reasoning skills and interpersonal resources to cope with dilemmas involving insufficient time for clients and stress due to high caseload and work demands. Supportive training and continuing education opportunities on the use of client-centred assessments and interventions may serve to address these and other problems encountered by occupational therapists in the mental health area in Sweden.

\section{Limitations}

The sample used in this study included 670 Swedish occupational therapists who were registered with the Swedish occupational therapy association as working in mental health. 285 participated in the study by completely or partially completing the questionnaire. The low response rate was a limitation of this study that may have been due to a number of reasons. First, some of the therapists registered as working in direct clinical care were no longer working directly with clients. Additionally, other potential respondents were sick-listed, on parental leave, or no longer working in the field of mental health. Another reason for the lower response rate may have been the combination of high workload demands and the length and density of the questionnaire. A second limitation of this study involved the fact that this was a survey study that utilized a non-standardised questionnaire. Although it was pilot tested for face validity and overall comprehension, its psychometric properties were not established. Thus, the interpretations and conclusions drawn from this study must consider the potential for bias due to unanticipated limitations inherent in the questionnaire. 


\section{Conclusion}

Despite its limitations, it can be argued that this study resulted in some important, preliminary information about client participation in occupational therapy. Most therapists practicing in the area of mental health in Sweden characterize their clients as interdependent in their approach to participation. Although more detailed information will be required to uncover the precise meaning of the term, interdependence, to these occupational therapists, the fact that the term implies a sense of reciprocity and power-sharing within the relationship is encouraging. Conversely, a more sobering finding is that many occupational therapists are concerned about barriers to clients' full participation in therapy. Interestingly, the occupational therapists locate those barriers as outside of themselves and view the clients' lack of abilities and organizational obstacles as central.

\section{Acknowledgements}

We especially thank Karin Sjöberg, RegOT, MSc OT, who completed the questionnaire and conducted the first survey, Kristin Alfredsson Ågren RegOT, MSc OT, for continuously support during the process. We also thank all the occupational therapists who completed and returned the questionnaires.

\section{References}

1. Hemmingsson H, Jonsson H. An occupational perspective on the concept of participation in the International Classification of Functioning, Disability and Health - Some critical remarks. Am J Occup Ther. 2005;59:569-76.

2. Kielhofner G. Therapeutic reasoning: Using occupational therapy’s conceptual foundations in everyday practice. In Kielhofner G. Conceptual foundations of occupational therapy, $4^{\text {th }}$ ed. Philadelphia: FA Davis Company. 2009:279-299. 
3. World Health Organization. International classification of functioning, disability and health. Geneva: World Health Organization; 2001.

4. Kielhofner G. Model of Human Occupation: Theory and application. $4^{\text {th }}$ ed. Baltimore: Lippincott Williams \& Wilkins; 2008

5. United Nations. The Convention on the Rights of Persons with Disabilities. UN. 2006. Available at: http://www.un.org. (Accessed 23 August 2010).

6. Creek J, Lawson-Porter A. Contemporary issues in occupational therapy. Reasoning and reflection. West Sussex: John Wiley \& Sons Ltd; 2007.

7. Vessby K, Kjellberg A. Participation in occupational therapy research - A literature review. Br J Occup Ther. 2010;73:319-26.

8. Taylor R.R. The intentional relationship. Occupational therapy and use of self. Philadelphia: F.A. Davis Company; 2008.

9. Maitra K.K, Erway F. Perception of Client-centred practice in occupational therapists and their clients. Am J Occup Ther. 2006;60:298-10.

10. Palmadottir G. Client-therapist relationships: Experiences of occupational therapy clients in rehabilitation. $\mathrm{Br}$ J Occup Ther. 2006;69:394-01.

11. Townsend E. Enabling occupation: An occupational therapy perspective. Ottawa: Canadian Association of Occupational Therapists; 2002.

12. Sumsion T. Facilitating client-centered practice: Insights from clients. Can J Occup Ther. 2005;72:13-20. 
13. Hedberg-Kristensson E, Dahlin Ivanoff S, Iwarsson S. Participation in the prescription process of mobility devices: Experience among older patients. Br J Occup Ther. 2006; 69:169-76.

14. Kielhofner G, Taylor R.R. Re-defining client-centered practice in occupational therapy. Paper presented for the Italian Occupational Therapy Association. Naples, Italy; 2010.

15. Law M. Baptiste S. Mills J. Client-centred practice: what does it mean and does it make a difference? Can J Occup Ther. 1995;62:250-57.

16. SFS 1982:763. Hälso- och sjukvårdslagen. (The health and medical services act). In Swedish. Stockholm: Socialdepartementet.

17. SFS 1993:387. Lagen om stöd och service till vissa funktionshindrade. (The act concerning support and service for persons with certain functional impairments). In Swedish. Stockholm: Socialdepartementet.

18. SFS 2001:453. Socialtjänstlagen. (The social services act). In Swedish. Stockholm: Socialdepartementet.

19. Swedish Association of Occupational Therapists. Code of ethics for occupational therapists. Nacka: Swedish Association of Occupational Therapists; 2005.

20. Larsson Lund M, Tamm, M, Bränholm I-B. Patients perceptions of their participation in rehabilitation planning and professionals` view of their strategies to encourage it. Occup Ther Intern. 2001;8:151-67.

21. Palmadottir G. Client perspectives on occupational therapy in rehabilitation service. Scand J OccupTher. 2003; 10:157-66

22. Goodley D. Self-advocacy in the lives of people with learning difficulties. Buckingham Philadelphia: Open University Press; 2000. 
23. Vetenskapsrådet. Forskningsetiska principer i humanistisk-samhällsvetenskaplig forskning (Research ethical principles in humanistic and social science). In Swedish. Available at http://www.codex.vr.se/texts/HSFR.pdf. (Accessed 23 August 2010).

24. Swedish Association of Occupational Therapists. Available at http://www.fsa.akademikerhuset.se (Accessed 19 September 2005).

25. Kjellberg A. More or less independent. Disabil Rehabil. 2002;24:828-40.

26. Kinebanian A, Stomph M. Cross-cultural occupational therapy: A critical reflection. Am J Occup Ther. $1992 ; 46: 751-57$

27. Whiteford G.E, Wilcock AA. Cultural relativism: Occupation and independence reconsidered. Can J Occup Ther. 2000;67:324-36.

28. Rogers, C.R. On becoming a person: a therapist's view of psychotherapy. New York: Houghton Mifflin; 1961. 


\section{Legends of tables}

Table I. Participants' fields of practice $(\mathrm{N}=222)$

Table II. Participants' further higher education $(\mathrm{N}=223)$

Table III. Primary Barrier to Client Participation 
Table I. Participants' fields of practice $(\mathrm{N}=222)$

Field of practice ${ }^{1}$

Daily activities/work

Residential facilities and daily activities/work in municipalities

Out-patient treatment

Hospital treatment

Residential facilities in municipalities

Hospital and Out-patient treatment

Others

${ }^{1}$ Missing data: 63
N $\%$

$65 \quad 29$

$60 \quad 27$

$44 \quad 20$

$25 \quad 11$

$16 \quad 7$

105

21 
Table II. Participants' further higher education $(\mathrm{N}=223)$

Further higher education ${ }^{1}$

No further higher education

Further higher education outside the occupational therapy field

Complementary academic levels courses

Other further higher education courses within the occupational therapy field

${ }^{1}$ Missing data: 62
N $\%$

$84 \quad 52$

$68 \quad 24$

$46 \quad 15$

259 
Table III. Primary Barrier to Client Participation

$\begin{array}{ll}\text { Barrier } & \text { N }\end{array}$

The client's lack of ability to participate, meaning to describe his or her $97 \quad 39$ experience of the problem, to define objectives and goals and to choose appropriate strategies

$\begin{array}{lll}\text { Organizational and financial problems } & 51 \quad 20\end{array}$

The client's lack of knowledge about the problem and how it might be able to $40 \quad 16$ be solved.

$\begin{array}{lll}\text { The client and the occupational therapist priority is not equal } & 18 & 7\end{array}$

$\begin{array}{lll}\text { Working procedures of the team } & 15 \quad 6\end{array}$

Lack of evaluation tools, theories and models that support participation $\quad \begin{aligned} & 9 \\ & 4\end{aligned}$

$\begin{array}{lll}\text { The clients deficient ability to communicate verbally } & 7 & 3\end{array}$

$\begin{array}{lll}\text { Others } & 13 \quad 5\end{array}$ 